\title{
Effect of tiotropium on health-related quality of life as a primary efficacy endpoint in COPD
}

\author{
A-B Tonnel' \\ T Perez' \\ J-M Grosbois ${ }^{2}$ \\ C Verkindre ${ }^{2}$ \\ M-L Bravo ${ }^{3}$ \\ $M$ Brun $^{3}$ \\ on behalf of the TIPHON \\ study group ${ }^{a}$ \\ 'Centre Hospitalier Régional \\ Universitaire (CHRU) de Lille, \\ Lille Cedex, France; ${ }^{2}$ Centre \\ Hospitalier de Béthune, Béthune, \\ France; ${ }^{3}$ Boehringer Ingelheim France, \\ Reims Cedex, France \\ asee Appendix: participating \\ investigators
}

\begin{abstract}
Clinical manifestations of chronic obstructive pulmonary disease (COPD), including airflow limitation, dyspnea, and activity limitation, ultimately lead to impaired health-related quality of life (HRQoL). This 9-month, randomized, double-blind, multicenter study compared the effect of once-daily tiotropium $18 \mu \mathrm{g}$ and placebo on HRQoL, spirometric parameters, and exacerbations in 554 patients with moderate-to-severe COPD. HRQoL was assessed using the St. George's Respiratory Questionnaire (SGRQ) and the new 8-item Visual Simplified Respiratory Questionnaire (VSRQ), which is currently being validated. The primary efficacy endpoint was the proportion of patients achieving a reduction of at least 4 units in the SGRQ total score at study end (Month 9). Mean \pm SD baseline SGRQ total score was $47.4 \pm 18.1$. Significantly more tiotropium-treated patients achieved a reduction of at least 4 units in the SGRQ score vs placebo at study end $(59.1 \%$ vs $48.2 \%$, respectively; $p=0.029)$. Tiotropium significantly improved spirometric parameters (forced expiratory volume in 1 second $\left[\mathrm{FEV}_{1}\right]: 0.11 \pm 0.02$ L vs $0.01 \pm 0.02 \mathrm{~L}$; between-group difference: $0.10 \pm 0.03 \mathrm{~L}, \mathrm{p}=0.0001$ ) and reduced exacerbations vs placebo. Maintenance treatment with tiotropium provided significant and clinically relevant improvements in HRQoL, as measured by the SGRQ.
\end{abstract}

Keywords: chronic obstructive pulmonary disease, long-acting anticholinergic, health-related quality of life, tiotropium

\section{Introduction}

Chronic obstructive pulmonary disease (COPD) is characterized by airflow limitation that is not fully reversible (Global Initiative for Chronic Obstructive Lung Disease 2006). Even with the best available care, lung function in patients with COPD progressively worsens over time. Maintaining or improving health-related quality of life (HRQoL) is, therefore, a key treatment goal in COPD and should be one of the main parameters for monitoring the disease and assessing the efficacy of treatment.

Clinical trials have widely employed health status questionnaires as markers of the impact of disease on patients' health, daily life, and sense of well-being (Spencer et al 2001, 2004; Jones et al 2003). Many HRQoL questionnaires exist, including disease-specific instruments such as the St. George's Respiratory Questionnaire (SGRQ) (Jones et al 1992) and generic instruments such as the 36-item short form (SF-36) (McHorney et al 1993). These questionnaires have been used in patients with stable COPD and during exacerbations (Spencer et al 2004), as well as in the evaluation of new therapies (Spencer et al 2001; Jones et al 2003). In particular, the SGRQ has been validated in many languages, including French (Bourbeau et al 2004).

Despite the existence of numerous HRQoL questionnaires, none has been specifically designed and validated for use in the treatment of COPD in routine medical practice. Indeed, PW Jones recently highlighted the issue that tools used to assess HRQoL in clinical trials by pharmaceutical companies and/or payers should be differentiated from those designed to detect an improvement in HRQoL in an individual 
patient (Jones 2006). HRQoL is not easy to measure in routine medical practice. The lack of a convenient tool in French instigated the development of the disease-specific Visual Simplified Respiratory Questionnaire (VSRQ) by Boehringer Ingelheim, France. The focus of this paper is on the efficacy of tiotropium compared with placebo on HRQoL as measured by the SGRQ. The VSRQ questionnaire has been included in this study to undergo a preliminary evaluation, but the data on the validation of this new instrument will not be the subject of the current paper and will be published elsewhere.

Tiotropium (Spiriva ${ }^{\circledR}$; Boehringer Ingelheim $\mathrm{GmbH}$; Ingelheim am Rhein, Germany) is a once-daily anticholinergic that provides effective 24-hour efficacy through prolonged $\mathrm{M}_{3}$-receptor blockade and is indicated for maintenance treatment of patients with COPD. Previous studies have consistently shown that tiotropium significantly improves lung function, favorably influences exercise capacity, reduces dyspnea and also the incidence of exacerbations in patients with COPD (Casaburi et al 2002; Vincken et al 2002; Brusasco et al 2003; Celli et al 2003; O'Donnell et al 2004; Niewoehner et al 2005; Verkindre et al 2005; Dusser et al 2006). It has also been shown to improve HRQoL compared with placebo (Casaburi et al 2002; Donohue et al 2002; Vincken et al 2002; Verkindre et al 2005). Furthermore, tiotropium has been shown to be superior to placebo in terms of the proportion of patients achieving a reduction of at least 4 units in the SGRQ total score (Donohue et al 2002). However, these studies monitored HRQoL only as a secondary efficacy parameter.

The primary aim of the present study was to investigate the effects of 9 months' treatment with tiotropium $18 \mu \mathrm{g}$ on HRQoL in patients with moderate-to-severe COPD, using the SGRQ. The assessment of HRQoL as a primary endpoint has, to our knowledge, not been previously evaluated in any other clinical trials of pharmacologic interventions in COPD.

\section{Materials and methods}

\section{Patients}

Male and female outpatients aged $\geq 40$ years with a clinical diagnosis of COPD (pre- and post-bronchodilator $\mathrm{FEV}_{1}$ $20 \%-70 \%$ predicted and $\mathrm{FEV}_{1} /$ slow vital capacity [SVC] $\leq 70 \%$,) corresponding to mild, moderate, or severe COPD according to 1995 American Thoracic Society criteria (American Thoracic Society 1995) and a smoking history of $>10$ pack-years were eligible for inclusion in the study. Exclusion criteria were a history of asthma, allergic rhinitis, or atopy; regular use of daytime oxygen therapy; a recent respiratory tract infection (within the previous 6 weeks); a recent history of myocardial infarction (within the previous 6 months); cardiac arrhythmia requiring drug therapy (within the previous year); or hospitalization for either heart failure or pulmonary edema (within the previous 3 years).

\section{Study design}

This was a 9-month, randomized, double-blind, placebocontrolled, multicenter, parallel-group study. The trial (protocol 205.256) was performed at 123 centers in France. Patients were recruited between May 2002 and June 2003, and follow up was from August 2002 through April 2004. The trial was approved by an ethics committee (Comite Consultatif de Protection des Personnes dans la Recherche Biomedicale [CCPPRB] of Lille), conducted in accordance with the Declaration of Helsinki, and all patients provided written informed consent.

Following a screening visit (Day -14), eligible patients underwent a 2-week run-in period during which any shortacting anticholinergics or long-acting $\beta_{2}$-agonists were washed out. On Day 1 of the study, patients were randomized $1: 1$ to receive either tiotropium $18 \mu \mathrm{g}$ once daily or placebo, delivered via the HandiHaler ${ }^{\circledR}$ device (Boehringer Ingelheim $\mathrm{GmbH}$; Germany). Patients were assigned using a computergenerated randomization schedule, with no stratification (block size of 4).

Patients were permitted to use salbutamol (Ventolin ${ }^{\circledR}$; GlaxoSmithKline, UK) delivered via a metered-dose inhaler, as needed, for acute symptom relief. Concomitant use of theophylline preparations (excluding 24-hour preparations), mucolytics, inhaled corticosteroids (ICS), and oral steroids (at a dose of $<10 \mathrm{mg}$ prednisone daily or equivalent) was allowed if the dosage was stabilized for $\geq 6$ weeks before study entry. During the treatment period, patients were not allowed to use $\beta$-blockers, antileukotrienes, oral or inhaled long-acting $\beta_{2}$-agonists, short-acting anticholinergics, or any other investigational drug. One 10-day course of oral steroids was permitted for the treatment of a COPD exacerbation during the study period. Investigators were also permitted to administer antibiotics as deemed necessary for the treatment of exacerbations.

\section{Clinical assessments}

Assessments were conducted prior to administration of treatment on Day 1 (randomization) and after 3, 6, and 9 months of treatment. The primary efficacy endpoint was the proportion of patients achieving a reduction of at least 4 units in the SGRQ total score at study end (Month 9). In order to avoid the introduction of a bias in the completion 
of the HRQoL questionnaires, these were completed prior to the spirometric tests using the SGRQ and the VSRQ on each test day. The SGRQ consists of a 76-item questionnaire split into 3 components: symptoms (assessing distress due to respiratory symptoms), activity (assessing the effects of breathlessness on mobility and physical activity), and impact (assessing the psychosocial impact of disease). The SGRQ total score is a composite of the 3 component scores. Scores are weighted and range from 0 to 100 , with higher scores indicating a poorer HRQoL. Currently, a reduction of $\geq 4$ units is considered to be the minimal clinically important difference by the author of the questionnaire (Jones 2002), but this value is currently under debate and subject to review. Subgroup analyses were performed according to COPD severity, reversibility at baseline, ICS use and occurrence of exacerbations during the trial.

The VSRQ consists of 8 items (dyspnea, usual daily activities, social activities, quality of sleep, pleasure, energy, anxiety, and sexual life) that are each rated from 0 (extreme limitation) to 10 (no limitation) on a visual scale. The VSRQ total score is the sum of these 8 ratings. An increase indicates an improvement in health status. More details about the questionnaire and the validation data from this trial will be published elsewhere.

$\mathrm{FEV}_{1}$, forced vital capacity (FVC), inspiratory capacity (IC), SVC, and forced inspiratory volume in 1 second $\left(\mathrm{FIV}_{1}\right.$; measured at selected sites only) were recorded 30 minutes prior to dosing on Day 1 and approximately 24 hours after the previous dose of study medication at 3,6, and 9 months. All spirometric tests were conducted in triplicate, and the highest measurements were used in subsequent analyses.

Detailed information on exacerbations of COPD was also collected. An acute exacerbation was defined as a sustained worsening of the patient's COPD (from the stable state and beyond normal day-to-day variation) that was acute in onset and necessitated a change in regular medication (RodriguezRoisin 2000). Adverse events were monitored throughout the treatment period and coded according to the Medical Dictionary for Drug Regulatory Affairs, MedDRA version 7.0.

\section{Statistical analysis}

A sample size of 234 patients per treatment group was required to provide $80 \%$ power to detect a between-group difference of $13 \%$ in the primary endpoint (proportion of patients with $\geq 4$ units improvement in SGRQ total score). This difference corresponds to expected response rates of $32 \%$ and $45 \%$ in the placebo and tiotropium groups, respectively ( 2 -sided $\chi^{2}$ test at a $5 \%$ confidence level). The sample size calculation based on a $13 \%$ difference was determined considering the findings of the pooled results from two 6-month trials (Brusasco et al 2003) comparing tiotropium, salmeterol and placebo. The difference between tiotropium and placebo after 6 months was 10\%. The other data taken into consideration was the pooled analysis of two 1-year placebo-controlled tiotropium trials (Casaburi et al 2002), showing a difference of $19 \%$ after 12 months.

Due to the fact that this trial had a duration that is in between that of the two reference trials and, under the assumption that the HRQoL will deteriorate over time, the assumption of a $13 \%$ difference was taken. Another assumption was that the pattern of concomitant medication use has changed over time and that there is a higher likelihood of concomitant respiratory medication use in this trial, as compared with the earlier trials used as reference.

Efficacy was measured in the full analysis population, which included all randomized patients who received study medication and had baseline and at least 1 valid posttreatment measurement. This included patients who dropped out prematurely, but these patients were not followed up until the projected exit date from the trial. Patients who did not adhere to the protocol or who were treated for less than 30 days were excluded from the per-protocol analyses. The safety population included all randomized patients who received study medication. Missing individual SGRQ items were handled according to the questionnaire authors' recommendations: missing items from Part 1 or Part 2 (sections 1 and 7 [last part]) of the questionnaire were imputed as negative responses. If individual SGRQ items were missing from Part 2 (sections 2-6 and 7 [first part] of the questionnaire), the total weight was adjusted to take into account the missing values. If more than 10 items were missing in these sections, then the component score was not included in the subsequent analyses. The maximum numbers of missing items were 2, 4, and 6 for the symptoms, activity, and impacts components, respectively. Moreover, missing SGRQ component or total scores were imputed using the last observation carried forward method (except if Day 1 was the last visit, in which case the patient was excluded). The VSRQ total score was calculated from the 8 category scores. As there was no specific recommendation for handling missing data, the last observation carried forward method was used.

The primary endpoint was analyzed using the CochranMantel-Haenszel test, stratified by center. Analysis of covariance with terms for treatment was used for all the HRQoL and spirometric endpoints, with baseline data as covariates. Four subgroups were defined: $\mathrm{FEV}_{1}$ severity 
(below and above 50\% predicted value) and reversibility at baseline, use of concomitant inhaled corticosteroids (yes/no), and occurrence of exacerbations (yes/no) during the trial. The subgroup analysis of changes from baseline in SGRQ total scores was performed using an analysis of covariance model with the factors treatment, subgroup, and subgroup-bytreatment interaction with the baseline values as covariate.

The Fisher exact test was used to compare the frequency of exacerbations. The Wilcoxon-Mann-Whitney test was used to compare the number of exacerbations days. Exacerbation endpoints were calculated per patient per year by dividing the number of events by the treatment exposure and multiplying by 365.25 . Pairwise treatment comparisons of time to the first COPD exacerbation from Kaplan-Meier estimates were made using the log rank test.

\section{Results}

\section{Patients}

A total of 555 patients were randomized and 554 received treatment, with 266 receiving tiotropium and 288 receiving placebo (Figure 1). Patients who dropped out but had baseline and post-treatment data were included in the full analysis dataset, following the intent-to-treat principle. 492 patients (tiotropium, $n=247$; placebo, $n=245$ ) had sufficient data for inclusion in the full analysis population for the SGRQ total score analysis. More patients in the placebo group discontinued the trial than in the tiotropium group ( $25.7 \%$ vs $14.7 \%, p=0.0013$ ) (Figure 1 ). In general, the 2 treatment groups were well matched at baseline (Table 1). However, while the mean \pm SD baseline SGRQ total score for all patients was $47.4 \pm 18.1$, the mean SGRQ total score was significantly higher in the placebo group than the tiotropium group (difference, $3.2 ; \mathrm{p}=0.046$ ) (Table 1). Furthermore, the mean baseline SGRQ total score was significantly higher in the subgroup of patients with more severe disease $\left(\mathrm{FEV}_{1} \leq 50 \%\right.$ predicted $)$ than in patients with milder disease $\left(\mathrm{FEV}_{1}>50 \%\right.$ predicted) (49.7 vs 43.5 , respectively).

\section{HRQoL}

Compared with the placebo group, significantly more patients in the tiotropium group achieved a reduction of at least 4 units in the SGRQ total score at Month 9 (Figure 2). At study end, 59.1\% (146/247) patients in the tiotropium group had exceeded this threshold that is, despite ongoing discussions, currently regarded as a clinically meaningful improvement in SGRQ total score. These patients were considered as responders, compared with $48.2 \%(118 / 245)$ of patients in the

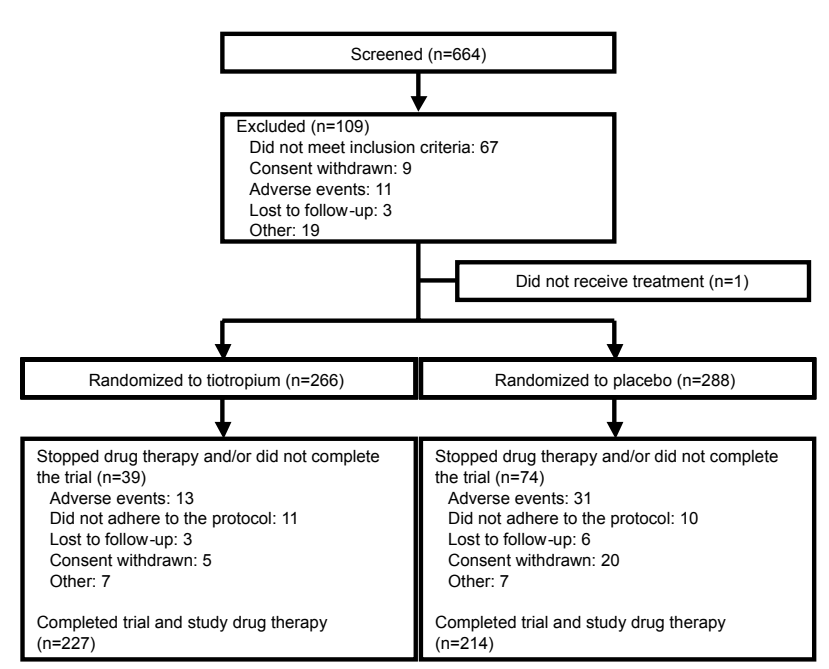

Figure I Trial flow chart.

placebo group (difference 10.9\% [95\% confidence interval (CI), $2.19 \%$ to $19.71 \%$ ]; $\mathrm{p}=0.029$ ).

Tiotropium significantly improved the SGRQ total score on each test day, compared with placebo (all p <0.05) (Figure 3a). At study end, adjusted mean (SE) change from baseline SGRQ total scores was -8.50 (0.90) for tiotropium and $-4.32(0.90)$ for placebo. The difference between the 2

Table I Patient demographics and characteristics at pretreatment baseline

\begin{tabular}{|c|c|c|}
\hline & Tiotropium & Placebo \\
\hline Patients, $\mathrm{n}$ & 266 & 288 \\
\hline Sex, M/F & $231 / 35$ & $246 / 42$ \\
\hline Age, years & $64.9 \pm 9.7$ & $63.5 \pm 10.1$ \\
\hline Body mass index, $\mathrm{kg} / \mathrm{m}^{2}$ & $26.0 \pm 4.8$ & $25.8 \pm 4.7$ \\
\hline Duration of COPD, years & $7.9 \pm 7.6$ & $8.0 \pm 7.9$ \\
\hline Smoking history, pack-years & $44.4 \pm 21.3$ & $43.0 \pm 22.5$ \\
\hline Current smokers, n (\%) & $63(23.7)$ & $87(30.2)$ \\
\hline \multicolumn{3}{|l|}{ HRQoL ${ }^{a}$} \\
\hline SGRQ total score & $45.8 \pm 17.7$ & $48.9 \pm 18.4$ \\
\hline VSRQ total score ${ }^{b}$ & $47.3 \pm 16.0$ & $43.3 \pm 16.9$ \\
\hline \multicolumn{3}{|l|}{ Pulmonary function } \\
\hline $\mathrm{FEV}_{1}, \mathrm{~L}^{\prime}$ & $1.38 \pm 0.44$ & $1.35 \pm 0.46$ \\
\hline $\mathrm{FEV}_{1}, \%$ predicted & $47.49 \pm 13.27$ & $46.19 \pm 12.40$ \\
\hline FVC, L & $2.50 \pm 0.68$ & $2.49 \pm 0.75$ \\
\hline $\mathrm{FEV}_{1} / \mathrm{FVC}, \%$ & $55.30 \pm 11.32$ & $54.62 \pm 11.27$ \\
\hline IC, L & $2.14 \pm 0.69$ & $2.09 \pm 0.69$ \\
\hline SVC, L & $2.78 \pm 0.74$ & $2.70 \pm 0.78$ \\
\hline $\mathrm{FIV}_{1}, \mathrm{~L}^{\mathrm{c}}$ & $2.02 \pm 0.64$ & $2.04 \pm 0.7 \mid$ \\
\hline Reversibility, n (\%) ${ }^{d}$ & $108(40.6)$ & $116(40.3)$ \\
\hline
\end{tabular}

Data are presented as mean \pm SD unless otherwise stated.

aLower SGRQ but higherVSRQ scores indicate an improvement.

'VSRQ total score was complete in 415 patients (tiotropium: $n=233$; placebo: $n=237$ ). ${ }^{\mathrm{C} F I V}$, was assessed only at selected sites ( $80.5 \%$ of patients in the full analysis population, tiotropium: $\mathrm{n}=233$; placebo: $\mathrm{n}=237$ ).

${ }^{d}$ Reversibility to a short-acting $\beta_{2}$-agonist. 
Tiotropium $(n=247) \quad \square$ Placebo $(n=245)$

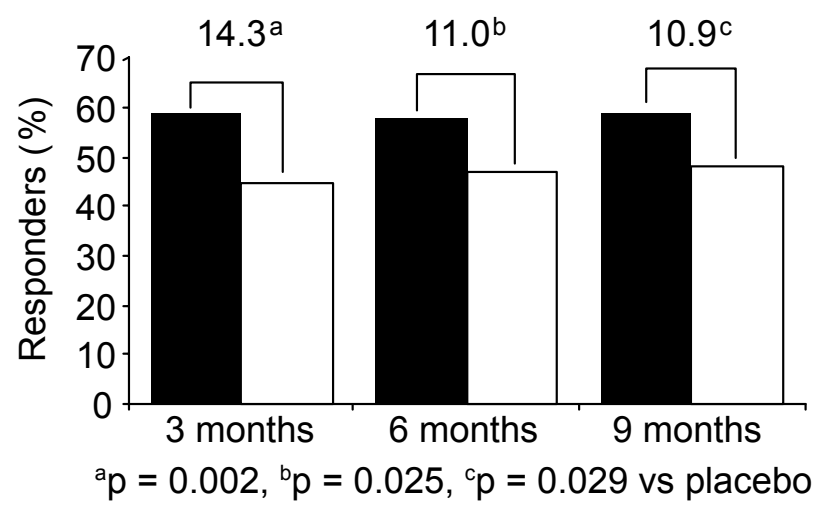

Figure 2 Percentage of responders (proportion of patients with at least 4 units improvement in SGRQ total score during the 9-month study).

groups exceeded the change of at least 4 units in the SGRQ total score currently regarded as meaningful (difference, -4.19 [95\% CI, -6.68 to -1.69$] ; \mathrm{p}=0.001)$. Furthermore, compared with placebo, tiotropium significantly improved all 3 SGRQ domain scores at study end (all $\mathrm{p}<0.05$ ) (Figure 3b).

When the overall study population is divided into subgroups according to baseline criteria (disease severity and reversibility), and on concomitant ICS use and exacerbations during the trial, tiotropium showed a consistent efficacy pattern across the subgroups. The interaction analysis of treatment by subgroup did not reveal any significant interactions (Table 2).

When we compared changes in SGRQ scores in 2 subgroups according to $\mathrm{FEV}_{1}$ values (higher or lower than $50 \%$ predicted), SGRQ total score improvement was statistically significantly better in more severe patients. The difference between the tiotropium and the placebo group was, despite the consistent effect of tiotropium, small and did not reach statistical significance in less severe patients. In patients receiving ICS, the difference in SGRQ between tiotropium and placebo did not reach statistical significance, most likely due to the low sample size that was not powered to detect a difference. When the change in the HRQoL is analyzed by the occurrence of exacerbations, patients in the placebo group do show a clear relationship between lesser improvement in HRQoL and the occurrence of at least one exacerbation. This difference is less pronounced in the patients on tiotropium treatment (Table 2).

\section{Spirometry}

At study end, tiotropium improved predose $\mathrm{FEV}_{1}, \mathrm{FIV}_{1}$, FVC, IC, and SVC compared with placebo (all p < 0.05) (Figure 4). (FIV ${ }_{1}$ was analyzed in $80.5 \%$ of the full analysis population.) There was no significant correlation between improvements in the SGRQ total score in both groups and changes in $\mathrm{FEV}_{1}(\mathrm{r}=-0.18), \mathrm{FIV}_{1}(\mathrm{r}=-0.14)$, FVC $(\mathrm{r}=-0.15)$, IC $(\mathrm{r}=-0.07)$, or SVC $(\mathrm{r}=-0.17)$ at study end. However, when we compared changes from baseline in SGRQ scores in 2 subgroups according to $\mathrm{FEV}_{1}$ values (higher or lower than $50 \%$ pred), SGRQ total score improvement was statistically significantly better in the more severe patients, in favor of the tiotropium group. In those with $\mathrm{FEV}_{1} \leq 50 \%$ pred, the difference between placebo and tiotropium in SGRQ improvement from baseline to 9 months was -6.00 points $(\mathrm{p}=0.0003)$ (Table 2$)$.

\section{Exacerbations}

Patients treated with tiotropium experienced significantly fewer exacerbations per year (1.05 vs $1.83,43 \%$ reduction; $\mathrm{p}=0.03)$ and exacerbation days per year (10.5 vs 20.6 , $49 \%$ reduction; $\mathrm{p}=0.02)$ than those treated with placebo (Table 3). A nonstatistically significant lower percentage of patients experienced 1 or more exacerbations during the 9-month study in the tiotropium group than in the placebo group $(38.0 \%$ vs $45.1 \%$; $=0.10)$. In addition, tiotropium significantly delayed the time to first exacerbation compared
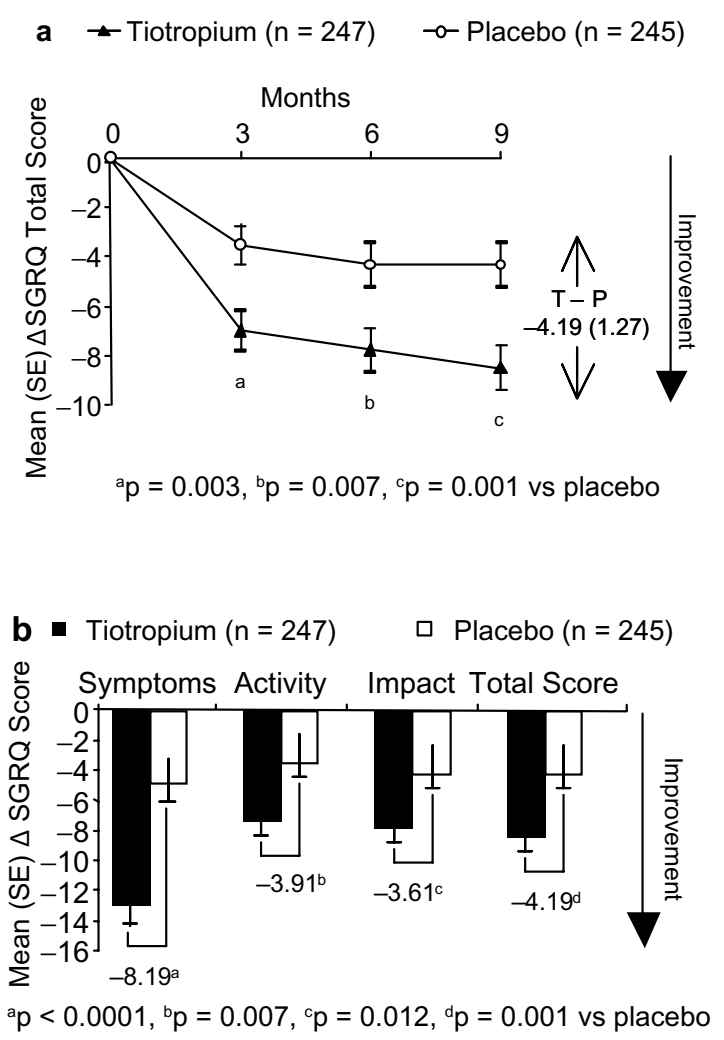

Figure 3 Adjusted mean (SE) change from baseline in SGRQ scores in patients taking tiotropium or placebo: a) change in total score during the 9-month study; and b) change in domain scores at study end (means adjusted for baseline SGRQ scores). 
Table 2 Mean change from baseline in SGRQ total score at study end according to COPD severity, reversibility at baseline, and ICS use during the trial

\begin{tabular}{|c|c|c|c|c|c|c|c|}
\hline & \multicolumn{2}{|c|}{ Tiotropium } & \multicolumn{2}{|c|}{ Placebo } & \multirow[b]{2}{*}{$\begin{array}{l}\text { Difference } \\
\text { (SE) }\end{array}$} & \multirow[b]{2}{*}{$95 \% \mathrm{Cl}$} & \multirow[b]{2}{*}{ p value } \\
\hline & $\begin{array}{l}\text { Number of } \\
\text { patients }\end{array}$ & $\begin{array}{l}\text { Mean (SE) } \Delta \\
\text { from baseline }\end{array}$ & $\begin{array}{l}\text { Number of } \\
\text { patients }\end{array}$ & $\begin{array}{l}\text { Mean (SE) } \Delta \\
\text { from baseline }\end{array}$ & & & \\
\hline \multicolumn{8}{|l|}{ COPD severity } \\
\hline $\mathrm{FEV}_{1}>50 \%$ predicted & 105 & $-8.85 \pm 1.37$ & 93 & $-7.38 \pm 1.44$ & $-1.47(1.99)$ & $-5.37,2.44$ & 0.4604 \\
\hline $\mathrm{FEV}_{1} \leq 50 \%$ predicted & 140 & $-8.18 \pm 1.18$ & 150 & $-2.18 \pm 1.14$ & $-6.00(1.64)$ & $-9.21,-2.78$ & 0.0003 \\
\hline \multicolumn{8}{|c|}{ ICS use } \\
\hline Not receiving ICS & 154 & $-9.22 \pm 1.13$ & 156 & $-4.81 \pm 1.13$ & $-4.41(1.60)$ & $-7.55,-1.27$ & 0.0061 \\
\hline Receiving ICS & 93 & $-7.32 \pm 1.46$ & 89 & $-3.45 \pm 1.49$ & $-3.87(2.09)$ & $-7.97,0.24$ & 0.0648 \\
\hline \multicolumn{8}{|l|}{ Reversibility ${ }^{\mathrm{a}}$} \\
\hline Yes & 101 & $-8.78 \pm 1.40$ & 100 & $-4.20 \pm 1.41$ & $-4.58(1.99)$ & $-8.49,-0.68$ & 0.0215 \\
\hline No & 143 & $-8.25 \pm 1.18$ & 144 & $-4.48 \pm 1.17$ & $-3.76(1.66)$ & $-7.02,-0.50$ & 0.0239 \\
\hline \multicolumn{8}{|l|}{ Exacerbation } \\
\hline Yes & 95 & $-7.21 \pm 1.44$ & 119 & $-2.15 \pm 1.28$ & $-5.06 \pm 1.92$ & $-8.84,-1.28$ & 0.0089 \\
\hline No & 152 & $-9.33 \pm 1.14$ & 126 & $-6.35 \pm 1.25$ & $-2.98 \pm 1.69$ & $-6.30,0.35$ & 0.0791 \\
\hline
\end{tabular}

Lower SGRQ total scores indicate an improvement.

Means are adjusted for baseline SGRQ total scores using the following analysis of covariance model: Change from baseline of SGRQ total score $=$ treatment + subgroup + subgroup-by-treatment interaction + baseline.

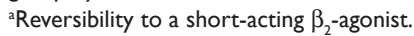

Full analysis set was analyzed. Number of patients with available data may differ in each subgroup.

The interaction of treatment and subgroup was not significant with p values of $0.0787,0.8364,0.7510$, and 0.4177 , respectively for severity of the illness, ICS use, reversibility, and exacerbation on treatment.

with placebo; mean time to first exacerbation was 201 days in the tiotropium group vs 181 days in the placebo group $(p=0.0081)$.

\section{Adverse events}

The proportion of patients experiencing an adverse event was similar in the tiotropium and placebo group (Table 4). The incidence of dry mouth was very low and similar in both groups (tiotropium, $1.1 \%$; placebo, $0.7 \%$ ). The proportion of patients with drug-related or serious adverse events or those withdrawing from the study due to adverse events or death were not significantly different (Table 4 ). The number of deaths occurring during the study ( 3 in the tiotropium group and 6 in the placebo group) was not unexpected,

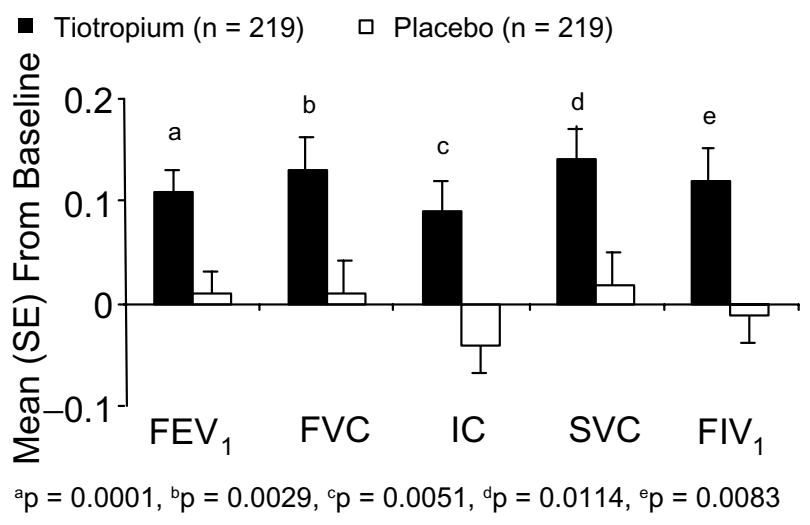

Figure 4 Adjusted mean (SE) change from baseline in spirometric parameters at study end (means adjusted for baseline values). given the age, severity of COPD, and prevalence of other serious comorbid conditions in the study population. There were 3 deaths in the tiotropium group (stroke (1), COPD (2)) and 6 deaths in the placebo group (COPD (1), pneumonia (1), suicide (2), respiratory failure (1) and aortic aneurysm (1)).

\section{Discussion}

A fundamental aim of COPD management is to improve HRQoL. This 9-month study found that significantly more patients who received maintenance treatment with tiotropium $18 \mu \mathrm{g}$ daily had a reduction of at least 4 units in the SGRQ total score in their HRQoL compared with those who received placebo. The clinical significance of the modification of -4 units is a matter of considerable discussion in the literature, including that authored by Dr Jones himself. However, the value of -4 units will be maintained to facilitate the discussion of the results obtained in this study.

These findings are consistent with previous studies that have shown significant improvements in SGRQ component and total scores with tiotropium (Donohue et al 2002; Casaburi et al 2002; Vincken et al 2002; Brusasco et al 2003; Verkindre et al 2005). The percentage of patients in the placebo group who had a reduction of at least 4 units in the SGRQ total score in this trial was somewhat higher (48\%) compared with previous studies (30\%-39\%) (Casaburi et al 2002; Brusasco et al 2003; Verkindre et al 2005), although 
Table 3 Percentage of patients with $\geq I$ exacerbation, and mean number of exacerbations and exacerbation days per patient per year

\begin{tabular}{llllll}
\hline & Tiotropium & Placebo & Difference & 95\% Cl & P value \\
\hline Patients with $\geq \mathrm{I}$ exacerbation, \% & 38.0 & 45.1 & -7.2 & $-15.4,1.00$ & 0.1013 \\
Number of exacerbations/patient/year, $\mathrm{n}$ & 1.05 & 1.83 & -0.77 & $-1.37,-0.20$ & 0.0287 \\
Number of exacerbation days/patient/year, days & 10.5 & 20.6 & -10.1 & $-16.5,-3.64$ & 0.0213 \\
\hline
\end{tabular}

the proportions are similar to those reported by Donohue et al (tiotropium: 51\%; placebo: 42\%) (Donohue et al 2002). While more placebo-treated patients withdrew from the study than those receiving tiotropium, this does not entirely explain the high placebo response as missing scores were imputed. The present study was performed over a 2-year period, with about $50 \%$ of patients identified and recruited in the first year; however, there was no change in COPD management during the 2 years. Therefore, there is no clear explanation for the higher-than-expected proportion of placebo-treated patients with HRQoL improvements. These levels for placebo responders are consistent with data from 4 internal studies of tiotropium, where the rate of placebo response was $29 \%-42 \%$ (data on file, Boehringer Ingelheim).

Nevertheless, the higher-than-expected percentage of responders in the placebo group is possibly explained by the focus of both patients and physicians on monitoring HRQoL as the primary endpoint of the trial. Furthermore, both may be supposed to have had higher expectations of the effect of tiotropium as the study was conducted at a time when tiotropium was already available in other European countries, but not in France: this assumption, nevertheless, remains hypothetical.

The mean SGRQ total score was significantly lower in the tiotropium group compared with the placebo group at baseline; however, all results presented are baseline adjusted.

Table 4 Adverse event profile

\begin{tabular}{lll}
\hline & Tiotropium & Placebo \\
\hline Patients, $\mathrm{n}$ & 266 & 288 \\
At least I adverse event & $162(60.9)$ & $193(67.0)$ \\
Drug-related adverse events & $12(4.5)$ & $8(2.8)$ \\
Deaths & $3(1.1)$ & $6(2.1)$ \\
Serious adverse events & $42(15.8)$ & $38(13.2)$ \\
Adverse events leading & $5(1.9)$ & $16(5.6)$ \\
to discontinuation & & \\
Selected adverse events: & \\
$\quad$ COPD exacerbations & & $80(27.8)$ \\
Bronchitis & $65(24.4)$ & $33(11.5)$ \\
$\quad$ Superinfection of the lung & $27(10.2)$ & $20(6.9)$ \\
$\quad$ Rhinitis & $18(6.8)$ & $7(2.4)$ \\
\hline
\end{tabular}

Data expressed as $\mathrm{n}(\%)$ unless otherwise indicated. ${ }^{\mathrm{a}}$ Occurring in $3 \%$ or more of patients by treatment.
Two previous 1-year studies have assessed the effects of tiotropium on HRQoL compared with placebo or ipratropium (Casaburi et al 2002; Vincken et al 2002). In both these trials, improvement in SGRQ total scores reached a plateau after 3 to 6 months of treatment. Based on these data, 9 months was chosen as an appropriate timeframe for this study. However, future studies should address whether the observed improvements in HRQoL with tiotropium treatment are sustained over the longer term (Decramer et al 2004). Furthermore, future studies should compare the effects of tiotropium vs short-acting anticholinergics or long-acting $\beta_{2}$-agonists on HRQoL as a primary outcome.

We have conducted a number of subanalyses in this trial and tiotropium has consistently been shown to improve patients' HRQoL. As expected, the mean baseline SGRQ total score was significantly higher in patients with more severe disease $\left(\mathrm{FEV}_{1} \leq 50 \%\right.$ predicted $)$ than in those with milder disease $\left(\mathrm{FEV}_{1}>50 \%\right.$ predicted). In the subgroup analyses, tiotropium significantly improved SGRQ total score vs placebo in patients with more severe COPD ( $\mathrm{FEV}_{1} \leq 50 \%$ predicted). In the patients with milder COPD and $\mathrm{FEV}_{1}>50 \%$ predicted, this difference did not reach statistical significance, despite the consistent efficacy of tiotropium. This finding is due to an unexpectedly high response in the placebo group in this subanalysis. Why this high response occurred cannot be explained from the data, due to the small subgroups analyzed here and the resulting lack of power, the possibility of a chance finding cannot be excluded. Another potential explanation could be that the differences in the drop-out rates between tiotropium and placebo might have contributed to this finding, but this remains speculative.

Compared with placebo, tiotropium also provided significantly greater improvements in SGRQ total score in patients not receiving ICS during the trial. In the subgroup of patients receiving ICS, there was a trend towards a significant improvement vs placebo and a statistically significant change vs baseline.

HRQoL has been recognized as a key outcome measure in COPD as it has been associated with lung function decline, exercise performance, and healthcare utilization 
(Decramer et al 2005). Although the SGRQ has been proved unequivocally to be a useful tool to measure HRQoL in clinical trials, this large 76-item questionnaire is difficult to use for assessing individual patients in daily medical practice. Another recently developed instrument, the self-administered chronic respiratory questionnaire (CRQ), may be useful in clinical practice but had not been validated in French at the time of the study (Schunemann et al 2005). For this reason, the shorter 8-item VSRQ (French language version) has been developed and included in the present study. The VSRQ has the advantages of being both easy to use and unidimensional. However, further studies are needed to confirm its clinical responsiveness in individual patients.

In agreement with observations from previous largescale clinical studies (Casaburi et al 2002; Vincken et al 2002; Brusasco et al 2003; Celli et al 2003), tiotropium significantly improved spirometric parameters vs placebo. The physiologic hallmark of COPD is expiratory flow limitation (O’Donnell et al 1998, 1999). In this study, treatment with tiotropium led to significant improvements in $\mathrm{FEV}_{1}, \mathrm{FIV}_{1}, \mathrm{FVC}, \mathrm{IC}$, and SVC compared with placebo. We hypothesize that the observed improvement in airflow and reduction in hyperinflation (measured by FVC, IC, and SVC) with tiotropium plays a major role in dyspnea relief, which allows patients to increase their day-to-day activity, thereby improving their HRQoL. Increasing evidence suggests that $\mathrm{FEV}_{1}$ is only weakly correlated with patientcentered outcomes, with consistently low correlation between lung function and SGRQ total scores (O'Donnell et al 1998, 1999). In agreement with these findings, we did not find a relevant correlation between improvements in $\mathrm{FEV}_{1}$ and SGRQ total score at study end. In addition, this was the first study to investigate the impact of tiotropium

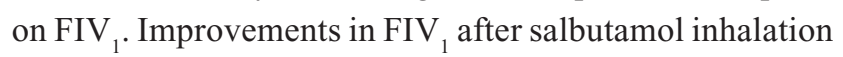
have been shown to be closely correlated with dyspnea relief at rest (Taube et al 2000). Tiotropium significantly improved this lung function parameter to a similar extent as $\mathrm{FEV}_{1}, \mathrm{FVC}, \mathrm{IC}$, and SVC.

Tiotropium also significantly reduced the frequency of exacerbations and the number of exacerbation days over the 9-month treatment period. Since exacerbations have been shown to adversely affect patients' health status (Kessler et al 2006; Celli et al 2007), a reduction in their frequency, the number of exacerbation days, or the time to first exacerbation, for example, would be highly likely to be associated with an improvement in patients' HRQoL.

In summary, compared with placebo, maintenance treatment with tiotropium $18 \mu \mathrm{g}$ daily for 9 months provides statistically and clinically significant improvements in HRQoL in patients with COPD, assessed using the SGRQ. These results cannot be extrapolated to patients who require daytime oxygen therapy or have a significant disease other than COPD. In addition, tiotropium significantly improved spirometric parameters and reduced the incidence of exacerbations and the number of exacerbation days in patients with COPD.

\section{Acknowledgments}

The authors recognize the contribution of the trial investigators and acknowledge the provision of medical writing services from PAREXEL MMS. Mapi Values, Lyon, France, contributed to the development of the VSRQ.

\section{Disclosures}

Professor Tonnel serves on the French Advisory Board Committees for Boehringer Ingelheim France, AstraZeneca, GlaxoSmithKline, and Novartis. Dr Perez receives research support from Boehringer Ingelheim France. Drs Bravo and Brun are employees of Boehringer Ingelheim France. Drs Grosbois and Verkindre have no conflict of interest. The study was funded by Boehringer Ingelheim France and Pfizer France.

\section{Referencess}

American Thoracic Society. 1995. Standards for the diagnosis and care of patients with chronic obstructive pulmonary disease. Am J Respir Crit Care Med, 152(5 Pt 2):S77-121.

Bourbeau J, Maltais F, Rouleau M, et al. 2004. French-Canadian version of the Chronic Respiratory and St George's Respiratory questionnaires: an assessment of their psychometric properties in patients with chronic obstructive pulmonary disease. Can Respir J, 11:480-6.

Brusasco V, Hodder R, Miravitlles M, et al. 2003. Health outcomes following treatment for six months with once daily tiotropium compared with twice daily salmeterol in patients with COPD. Thorax, 58:399-404.

Casaburi R, Mahler DA, Jones PW, et al. 2002. A long-term evaluation of once-daily inhaled tiotropium in chronic obstructive pulmonary disease. Eur Respir J, 19:217-24.

Celli B, ZuWallack R, Wang S, et al. 2003. Improvement in resting inspiratory capacity and hyperinflation with tiotropium in COPD patients with increased static lung volumes. Chest, 124:1743-48.

Celli BR, Barnes PJ. 2007. Exacerbations of chronic obstructive pulmonary disease. Eur Respir J, 29:1224-38.

Decramer M, Celli B, Tashkin DP, et al. 2004. Clinical trial design considerations in assessing long-term functional impacts of tiotropium in COPD: the UPLIFT trial. COPD, 1:303-12.

Decramer M, Gosselink R, Rutten-van Molken M, et al. 2005. Assessment of progression of COPD: report of a workshop held in Leuven, 11-12 March 2004. Thorax, 60:335-42.

Donohue JF, van Noord JA, Bateman ED, et al. 2002. A 6-month, Placebo-controlled study comparing lung function and health status changes in COPD patients treated with Tiotropium or salmeterol. Chest, 122:47-55.

Dusser D, Bravo ML, Iacono P. 2006. The effect of tiotropium on exacerbations and airflow in patients with COPD. Eur Respir J, 27:547-55.

Global Initiative for Chronic Obstructive Lung Disease. Global strategy for the diagnosis, management, and prevention of chronic obstructive pulmonary disease. [online]. Accessed August 31st 2007. URL: http://www.goldcopd.com. 
Jones PW, Willits LR, Burge PS, et al. 2003. Disease severity and the effect of fluticasone propionate on chronic obstructive pulmonary disease exacerbations. Eur Respir J, 21:68-73.

Jones PW, Quirk FH, Baveystock CM, et al. 1992. A self-complete measure of health status for chronic airflow limitation. The St. George's Respiratory Questionnaire. Am Rev Respir Dis, 145:1321-27.

Jones PW. 2006. Health status: what does it mean for payers and patients? Proc Am Thorac Soc, 3:222-26.

Jones PW. 2002. Interpreting thresholds for a clinically significant change in health status in asthma and COPD. Eur Respir J, 19:398-404.

Kessler R, Stahl E, Vogelmeier C, et al. 2006. Patient understanding, detection, and experience of COPD exacerbations: an observational, interview-based study. Chest, 130:133-42.

McHorney CA, Ware JE Jr, Raczek AE. 1993. The MOS 36-Item ShortForm Health Survey (SF-36): II. Psychometric and clinical tests of validity in measuring physical and mental health constructs. Med Care, 31:247-63.

Niewoehner DE, Rice K, Cote C, et al. 2005. Prevention of exacerbations of chronic obstructive pulmonary disease with tiotropium, a once-daily inhaled anticholinergic bronchodilator: a randomized trial. Ann Intern Med, 143:317-26.

O'Donnell DE, Flüge T, Gerken F, et al. 2004. Effects of tiotropium on lung hyperinflation, dyspnea and exercise tolerance in patients with COPD. Eur Respir J, 23:832-40.

O’Donnell DE, Lam MIU, Webb KA. 1999. Spirometric correlates of improvement in exercise performance after anticholinergic therapy in chronic obstructive pulmonary disease. Am J Respir Crit Care Med, 160:542-49.
O'Donnell DE, Lam MIU, Webb KA. 1998. Measurement of symptoms, lung hyperinflation, and endurance during exercise in chronic obstructive pulmonary disease. Am J Respir Crit Care Med, 158:1557-65.

Rodriguez-Roisin R. 2000. Toward a consensus definition for COPD exacerbations. Chest, 117(suppl 2):398S-401S.

Schunemann HJ, Goldstein R, Mador MJ, et al. 2005. A randomised trial to evaluate the self-administered standardised chronic respiratory questionnaire. Eur Respir J, 25:31-40.

Spencer S, Calverley PM, Burge PS, et al. 2004. Impact of preventing exacerbations on deterioration of health status in COPD. Eur Respir J, 23:698-702.

Spencer S, Calverley PMA, Burge PS, et al. 2001. Health status deterioration in patients with chronic obstructive pulmonary disease. Am J Respir Crit Care Med, 163:122-28.

Taube C, Lehnigk B, Paasch K, et al. 2000. Factor analysis of changes in dyspnea and lung function parameters after bronchodilation in chronic obstructive pulmonary disease. Am J Respir Crit Care Med, 162:216-20.

Tonnel AB, Perez T, Grosbois JM, et al. 2005. Psychometric validation of the Visual Simplified Respiratory Questionnaire (VSRQ) in France for chronic obstructive pulmonary disease (COPD). Eur Respir J, 26(suppl 49):512.

Verkindre C, Bart F, Aguilaniu B, et al. 2005. The effect of tiotropium on hyperinflation and exercise capacity in chronic obstructive pulmonary disease. Respiration, 73:420-27.

Vincken W, van Noord JA, Greefhorst APM, et al. 2002. Improved health outcomes in patients with COPD during 1 yr's treatment with tiotropium. Eur Respir J, 19:209-16. 


\section{Appendix: participating investigators}

B Adam, MD, Montpellier; C Aldegheri, MD, Toulouse; J Almandoz, MD, Cambo-les-Bains; M Angebault, MD, Chevilly Larue; S Arab, MD, Lannion; T Arfi, MD, Nice; C Arvin-berod, MD, Saint-Pierre; P Assouline, MD, Longjumeau; H Audouin, MD, Nantes; M Balde, MD, Montceau-les-Mines; J Baumann, MD, Mulhouse; M-H Becquemin, MD, Paris; M Becu, MD, Chalons-en-Champagne; M Bellier, MD, Amelie-les-Bains Palalda; A Bensa, MD, Nice; M-C Berchier, MD, Hayange; C Bergoin, MD, Valenciennes; A Beurey, MD, Ferolles-Aattilly; J-F Bic, MD, Maxeville; T Bodez, MD, Paris; V Boisserie-Lacroix, MD, Bordeaux; P Botrus, MD, Hayange; L Boudoux, MD, Armentieres; M Boukhana, MD, Metz; S Boutet, MD, Nantes; G-R Boyer, MD, Nice; O Broc, MD, La Roche-sur-Yon; C Brousse, MD, Castelnau-le-Lez; D Caillaud, MD, ClermontFerrand; O Castelnau, MD, Saint-Laurent du Var; P Charles, MD, Strasbourg; J-P Chevalier, MD, Annecy; F Chiny, MD, Luneville; N Chollet, MD, Bordeaux; M Claussner Paulignan, MD, Forbach; J-C Cornu, MD, Verdun; L Courtois Delair, MD, Reuil Malmaison; I Court Fortune, MD, SaintPriest en Jarez; R Dalenne, MD, Hazebrouck; R Daures, MD, Arles; M-C de Thesut, MD, Reims; P de Rigal, MD, Camboles-Bains; J-M Degreef, MD, Boulogne; M Derollez, MD, Maubeuge; C Deswarte, MD, Lille; J-D Dewitte, MD, Brest; P Dore, MD, La Rochelle; L du Couedic, MD, Compiegne; P Dumont, MD, Chauny; G Durand, MD, Beziers; J-L Duriez, MD, Tourcoing; L Dussart, MD, Marseille; J-P Dussol, MD, Beziers; D Dutartre, MD, Niort; Y El Far, MD, Saintes; L Fakhfakh, MD, Maubeuge; E Fauchon, MD, St Julien en Genevois; L Fouquert, MD, Grasse; E Fournier, MD, Henin Beaumont; M-A Francais Mauffrey, MD, Epinal; J-R Gaillard, MD, Pezenas; G Garcia, MD, Cagnes-sur-Mer; B Gau, MD, Grasse; L Gaucher, MD, Tours; T Gervais de Lafond, MD, Marseille; D Giamarci, MD, Toulouse; A Givogre-Aribaud, MD, Rognac; P Greiller, MD, Ollioules; N Grunchec, MD, Cholet; D Guffroy, MD, Maubeuge; B Guillaud Segard, MD, Saint-Jean de Maurienne; C Guillaume Leriche, MD, Amiens; Y-L Guillot, MD, Brive la Gaillarde; B Guillou-Bideau, MD, Quimper; I Guyot, MD, Cagnes-sur-Mer; A Haddad, MD, Lourdes; P Henry,
MD, Bagnols-sur-Ceze; B Herer, MD, Ferolles-Attilly; A Higuera, MD, Sete; J-P Homasson, MD, Chevilly Larue; G Issartel, MD, Maxeville; P Jacqueme, MD, Aix-enProvence; O Jarry, MD, Chalons-sur-Saone; J-Y Jasnot, MD, Nantes; J Jaudel, MD, Saintes; T Jean, MD, Villeuneuve Saint-Georges; C Jeanjean, MD, Grenoble; H Kafe, MD, Saint-Quentin; D Krai, MD, Cholet; M Krebs, MD, Le Mans; A Le Dantec, MD, Saint Omer; T Langin, MD, Nyons; D Leclercq, MD, Graulhet; M Legendre, MD, Chamalieres; D Lemaitre, MD, Alencon; D Lemerre, MD, La Rochelle; C Leroyer, MD, Brest; G Letanche, MD, Venissieux; J-F Madinier, MD, Orleans; D Mas, MD, Nice; F Maurel, MD, Ales; A Merzoug, MD, Fougeres; L Meziane, MD, Montpellier; D Milosevic, MD, Reims; P Monzerian, MD, Perpignan; L Moreau, MD, Maxeville; B Mouget, MD, Vandoeuvre-les-Nancy; D Muller, MD, Montigny-lesMetz; E Nussbaum, MD, Briancon; N Oliver, MD, Lodeve; O Ortega, MD, Joigny; F Paganin, MD, Saint-Pierre; D Payerne, MD, Nantes; F Pellet, MD, Bordeaux Bastide; A Perche, MD, Orleans; T Perez, MD, Lille; JE Philippe, MD, Montelimar; B Picavet, MD, Reims; P Poubeau, MD, Saint-Pierre; A Prigent, MD, Rennes; M-C Pujazon, MD, Toulouse; M-C Quinquenel, MD, Chalons-en-Champagne; C Raspaud, MD, Toulouse; J Ratomaharo, MD, Athis Mons; D Recart, MD, Biarritz; P Richard, MD, Saint Omer; J-Y Rigault, MD, Lorient; R Roboubi, MD, Henin Beaumont; C Roge, MD, Morlaix; P Rohart, MD, Saint-Quentin; J-J Roujon, MD, Ollioules; K Sawaf, MD, Colmar; B Sanjuan, MD, Valence; A Scherpereel, MD, Lille; C Schmitz, MD, Colmar; J Schranz, MD, Brignoles; J-C Severac, MD, Beziers; C Sevette, MD, Perpignan; G Sfeir, MD, Dole; A Smolis, MD, Bethune; J-M Sorokaty, MD, Nimes; P Tarodo de la Fuente, MD, Castelnau-le-Lez; I Tillie Leblond, MD, Lille; N Tolstuchow, MD, Avrille; A-B Tonnel, MD, Lille; J Troussier, MD, Angers; J-M Tunon de Lara, MD, Pessac; JM Velardocchio, MD, Marseille; M Verdier, MD, Perpignan; S Verdier, MD, Perpignan; C Verkindre, MD, Bethune; R Vestri, MD, Hyeres; P Veve, MD, Orange; J-F Vidal, MD, Montelimar; M-A Vincent, MD, Toul; L Vives, MD, SaintGaudens; E Vonesch, MD, Mulhouse; P Zuck, MD, Metz; J Zulaica, MD, Cambo-les-Bains. 